\title{
Tracking the Potential-controlled Synthesis of Cu-nanocuboids and Graphene-covered Cu-nanocuboids Under Operando $\mathrm{CO}_{2}$ Electroreduction
}

\author{
Thanh Hai Phan ${ }^{\S[a]}$, Karla Banjac ${ }^{\S[a]}$, Fernando Cometto ${ }^{[a]}$, Federico Dattila ${ }^{[b]}$, Rodrigo García- \\ Muelas $^{[b]}$, Núria López ${ }^{[b]}$, and Magalí Lingenfelder*[a]
}

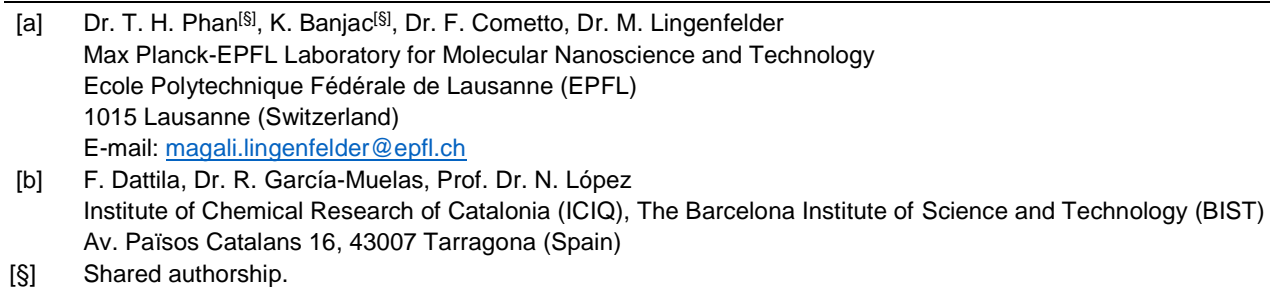

\begin{abstract}
:
The electroreduction of $\mathrm{CO}_{2}\left(\mathrm{CO}_{2} \mathrm{RR}\right)$ is a promising strategy towards sustainable fuels. $\mathrm{Cu}$ is the only earth-abundant catalyst capable of $\mathrm{CO}_{2}$-to-hydrocarbons conversion; yet, its dynamic structure under operando $\mathrm{CO}_{2} \mathrm{RR}$ conditions remains unknown. Here, we track the $\mathrm{Cu}$ structure operando by electrochemical scanning tunneling microscopy and Raman spectroscopy. Surprisingly, polycrystalline $\mathrm{Cu}$ surfaces reconstruct forming $\mathrm{Cu}$ nanocuboids whose size can be controlled by the polarization potential and the time employed in their in-situ synthesis, without the assistance of organic surfactants and-or halide anions. If the Cu-surface is covered by a graphene monolayer, smaller features with enhanced catalytic activity for $\mathrm{CO}_{2} \mathrm{RR}$ can be prepared. The graphene protecting layer soften the 3D morphological changes that $\mathrm{Cu}$-based catalysts suffer when exposed to aggressive electrochemical environments, and allows us to track the kinetic roughening process. This novel strategy is promising for improving $\mathrm{Cu}$ long-term stability and, consequently, controlling product selectivity.
\end{abstract}

The electrochemical reductive reaction responsible of the conversion of $\mathrm{CO}_{2}\left(\mathrm{CO}_{2} \mathrm{RR}\right)$ into hydrocarbons is a highly promising solution for the production of renewable fuels. ${ }^{[1]}$ One of the drawbacks of this technology is that most catalysts are not selective towards energy-rich $\mathrm{C}_{2+}$ fuels, and therefore their efficiency is limited. $\mathrm{Cu}$ is the only earth-abundant $\mathrm{CO}_{2} \mathrm{RR}$ catalyst capable of converting $\mathrm{CO}_{2}$ into hydrocarbons. ${ }^{[2-4]}$ Initial optimization towards enhanced ethylene production relies on a morphology-selectivity relationship highlighting (100) facets ${ }^{[5,6]}$ as ideal geometry for $\mathrm{C}-\mathrm{C}$ coupling. This reflects in an outstanding interest in the synthesis of $\mathrm{Cu}$ nanocuboids (CuNCs) through colloidal chemistry ${ }^{[7]}$, electrodeposition ${ }^{[8]}$, electrochemical cycling $^{[9]}$, thermally-grown ${ }^{[10]}$ or electrochemically-grown $\mathrm{Cu}$ oxides and halides. ${ }^{[11]}$

However, this morphology-selectivity trend based on post-mortem studies ignores the morphological evolution ${ }^{[12]}$ of the catalysts during $\mathrm{CO}_{2} \mathrm{RR}$. $\mathrm{Cu}$-based catalysts are highly dynamic: nanostructured electrocatalysts undergo fragmentation ${ }^{[13]}$ and coarsening $^{[14]}$, while surface reconstructions ${ }^{[15-17]}$ at the atomic scale occur on all $\mathrm{Cu}$ catalysts. These morphological changes greatly affect the catalysts' long-term stability (in terms of their
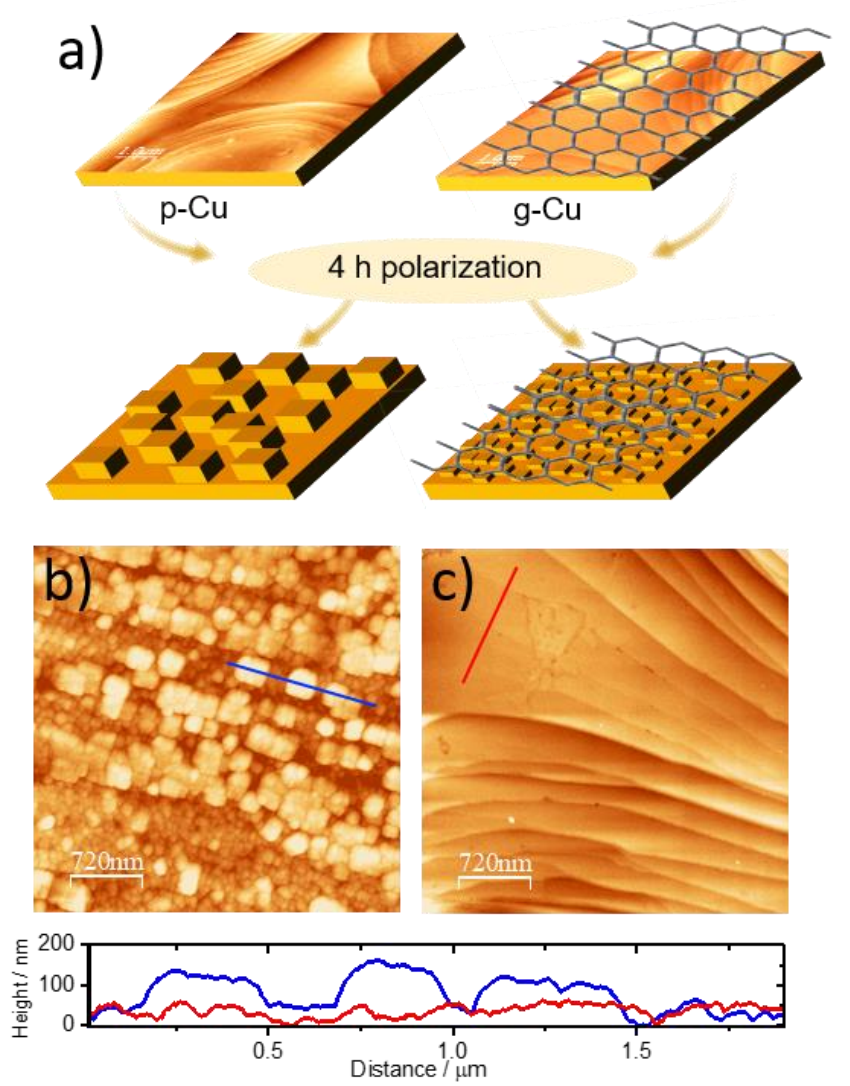

Figure 1. Scheme and ex-situ AFM images with corresponding height profiles showing the CuNCs formed on $a-b)$ a pristine polycrystalline $\mathrm{Cu}$-foil ( $\mathrm{p}-\mathrm{Cu})$ and c) a graphene-covered ( $\mathrm{g}-\mathrm{Cu}$ ) after polarization at $-1 \mathrm{~V}$ vs $\mathrm{Pt}$ in a $\mathrm{CO}_{2}$-saturated $0.1 \mathrm{M} \mathrm{KHCO}_{3}$ solution for 4 hours.

catalytic activity and product selectivity). ${ }^{[18,19]}$. The goal of operando studies investigating surface dynamics is thus threefold: first, to gain insight into the formation of CuNCs; second, to 
correlate operando surface dynamics with the trends reported in product evolution over time; third, to explore possible strategies for morphology conservation by, for example, covering the catalyst surface with $2 \mathrm{D}$ materials. ${ }^{[20]}$

In this communication, we show the morphological transformation that polycrystalline $\mathrm{Cu}(\mathrm{p}-\mathrm{Cu})$ and graphene-covered polycrystalline $\mathrm{Cu}(\mathrm{g}-\mathrm{Cu})$ surfaces undergo after potentiostatic polarization at $\mathrm{CO}_{2} \mathrm{RR}$ potentials over, at least, 4 hours. In-situ electrochemical scanning tunneling microscopy (EC-STM) experiments reveal the dynamics of the morphological evolution. Because $\mathrm{Cu}$ catalysts are highly prone to poisoning and deactivation during the first 30 minutes working at $\mathrm{CO}_{2} \mathrm{RR}$ regimes, $\mathrm{g}$-Cu represents an ideal substrate for these studies as graphene could act as a protective barrier. ${ }^{[21]}$ Moreover, fresh gCu samples are oxide-free. ${ }^{[22]}$ The thermal annealing of $\mathrm{Cu}$ foils under a reductive environment, performed as the pre-treatment step to CVD graphene growth, results in smooth surfaces ${ }^{[23]}$, hence allowing high-resolution EC-STM imaging over an enlarged potential window.

CuNCs, reported earlier in the literature, were synthesized by electroreduction of $\mathrm{Cu}$ oxide or halide films, electrodeposition or by colloidal chemistry (protected by organic surfactants). To the best of our knowledge, this is the first report on CuNCs preparation by the one-step massive reconstruction of a $\mathrm{Cu}$ surface upon potentiostatic polarization in a halide-free electrolyte Here, CuNCs growth during $\mathrm{CO}_{2} \mathrm{RR}$ is related to a surface reconstruction mainly governed by the polarization of the substrate, in agreement with the reports on surface reconstructions of $\mathrm{p}-\mathrm{Cu}$ to $\mathrm{Cu}(100){ }^{[15,17]}$ In order to exclude the role of $\mathrm{CO}_{2}$ on the mechanism of CuNCs formation, the same preparation protocol was conducted in a $\mathrm{CO}_{2}$-free electrolyte, i.e. saturated with $\mathrm{N}_{2}$ : similar CuNCs were observed (Figure S2). This further supports a potential-driven surface reconstruction leading to CuNCs formation after prolonged exposure.

To gain knowledge on the surface reconstruction dynamics, we performed a series of in-situ EC-STM experiments to follow the transformation of the $\mathrm{p}-\mathrm{Cu}$ surface underneath graphene. STM offers the unique possibility to monitor preferentially either the graphene layer or the $\mathrm{Cu}$ underneath by changing the STM bias conditions. The EC-polarization potential, located at a more negative value than the $\mathrm{Cu}_{\mathrm{x}} \mathrm{O}$ reduction potentials, is keep constant at the positive edge of $\mathrm{CO}_{2} \mathrm{RR}$ and the hydrogen evolution reaction (HER) regime to avoid bubble evolution and interference of the Faradaic currents (crucial for in-situ EC-STM experiments). A dynamic observation of the different stages of the surface nanostructuration was followed by in-situ EC-STM on g$\mathrm{Cu}$ (Figures 2a-g and S3). The initial stages of the surface reconstruction (Figures $2 \mathrm{a}-\mathrm{c}$ ) show how the polycrystalline $\mathrm{Cu}$ underneath the graphene is initially reconstructed to $\mathrm{Cu}$ mesocrystals within the first hour. Then, further reconstruction leads to nanometer-wide $\mathrm{Cu}(100)$ facets (Figures $2 d-e$ ). Figure $2 e$ shows that the graphene layer is still present during this reconstruction.

Small cuboid-features gradually grow on top of the $\mathrm{Cu}(100)$ facets; their size is gradually reducing as a function of time (as seen in Figures. 2f-g') reaching to an average edge length of ca. $4 \pm 1 \mathrm{~nm}$ after 4 hours of polarization. The CuNCs size and the kinetics of formation can be tuned by changing the potentiostatic polarization time or applying more negative potential values (the more negative the potential value, the smaller the features and the shorter the times employed in the synthesis, Figure S4). DFT calculations proved that surface reconstruction is driven by surface polarization, see Supporting Discussion. Open facets such as $\mathrm{Cu}(100)$ store electrostatic energy more effectively than $\mathrm{Cu}(111)$ due to low coordination of surface Cu atoms (Figure S5S6), therefore at very negative potentials they are more stable than closed-packed domains (Figure S7). By having a lower curvature, smaller structures experience a higher electric potential than flat surroundings, thus they undergo further reconstruction toward nanocuboid features with even lower $\mathrm{Cu}$ coordination.

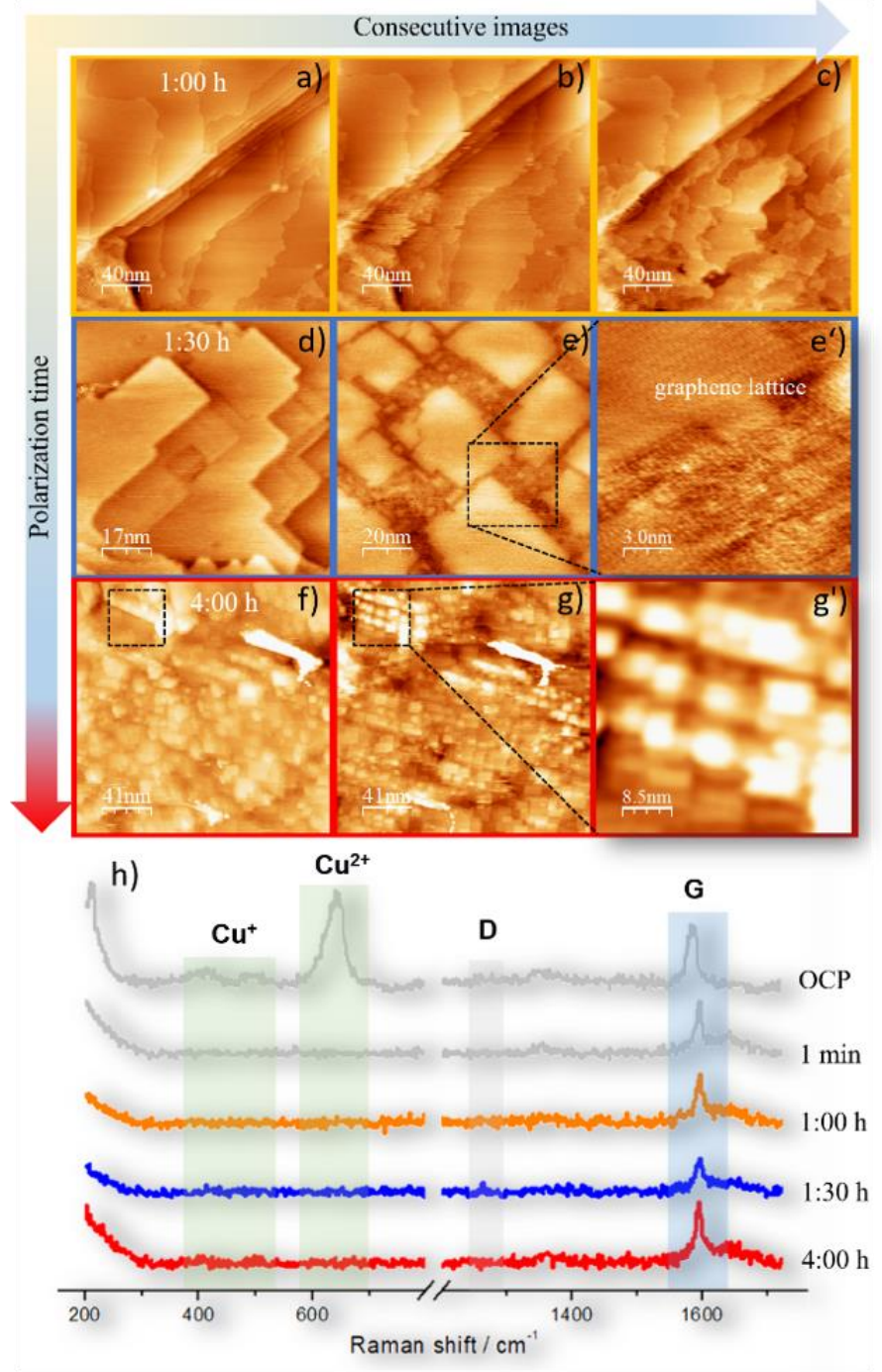

Figure 2. Series of EC-STM images showing the morphological evolution of a g-Cu surface upon polarization: a-c) from polycrystalline $\mathrm{Cu}$ to mesocrystals, $\mathrm{d}$ e') to $\mathrm{Cu}(100)$ facets and $\mathrm{f}-\mathrm{g}$ ') to nanocuboids. $E=-1.0 \mathrm{~V}$ vs Pt, $U_{b}=328 \mathrm{mV}$, I $=1.75 \mathrm{nA} . \mathrm{h}$ ) in-situ Raman spectra showing the immediate reduction of native $\mathrm{Cu}_{\times} \mathrm{O}$ to metallic $\mathrm{Cu}$ and the presence of graphene during CuNCs formation on g-Cu.

Operando Raman spectra (Figure $2 \mathrm{~h}$ ) show the absence of native copper oxides during the morphological evolution. The peaks 
attributed to $\mathrm{Cu}_{x} \mathrm{O}$ species ${ }^{[24,25]}\left(\approx 410-500 \mathrm{~cm}^{-1}\right.$ for $\mathrm{Cu}_{2} \mathrm{O}$ and $\approx 621$ $\mathrm{cm}^{-1}$ and $\mathrm{CuO}$, respectively) disappear at the beginning of reconstruction, indicating that the native oxide layer present in airexposed g-Cu surfaces was fully reduced. ${ }^{[26]}$ This is in agreement with our EC-STM measurements showing smooth metallic $\mathrm{Cu}$ terraces (Figures 2a-g).

Interestingly, the graphene remains almost invariant on top of the as-prepared CuNCs. Figures 3a-b show ex-situ STM images of gCu surfaces before and after EC treatment, respectively. It can be observed that the hexagonal lattice of graphene is still present on top of the CuNCs. This suggests that the graphene layer remains intact during the in-situ synthesis of the NCs. The persistence of the graphene layer was also confirmed by both operando (Figure 2h) and ex-situ Raman spectroscopy (Figure 3c), where ex-situ spectra were collected on the same $\mathrm{g}$-Cu sample before and after CuNCs formation. All spectra exhibit typical graphene peaks at $\approx 1591 \mathrm{~cm}^{-1}$ (the G band) and $\approx 2721 \mathrm{~cm}^{-1}$ (the $2 \mathrm{D}$ band). ${ }^{[27]}$ The absence of the $D$-band $\left(\approx 1350 \mathrm{~cm}^{-1}\right)$ on all spectra confirms the presence of a defect-free graphene layer before (i.e. on pristine $\mathrm{g}-\mathrm{Cu}$ ), during and after CuNCs formation. This further confirms that as-formed CuNCs are covered with graphene ( $g$-CuNCs).

Following the same procedure, similar scenarios were observed on $\mathrm{p}-\mathrm{Cu}$. That is, initially polycrystalline $\mathrm{Cu}$ evolves gradually to mesocrystals, $\mathrm{Cu}(100)$ facets and cuboids (Figure S8). These results indicate that different $\mathrm{Cu}$ surfaces form nanocuboids after prolonged exposition to $\mathrm{CO}_{2} \mathrm{RR}$ potentials (e.g. Cu foil, polished $\mathrm{Cu}, \mathrm{g}-\mathrm{Cu}, \mathrm{Cu}$ functionalized with molecular additives ${ }^{[28]}$ etc).

Even if the cuboid structures once formed conserve their morphology ex-situ at least for several days, a detailed analysis of the first steps in the formation of nanocuboid features points towards a kinetic roughening process, where multi-terrace islands (five-layered mounds, Figure S9) arise as a consequence of stepedge (Ehrlich-Schwoebel or ES) barriers ${ }^{[29,30]}$ inhibiting downward transport of adatoms.

The fact that these are far-from-equilibrium structures is consistent with the sharp straight steps edges along [010] and [001] $\mathrm{Cu}(001)$ directions, in contrast to the edge-rounded equilibrium structures seen after homoepitaxy of $\mathrm{Cu}$ on $\mathrm{Cu}(001){ }^{[31,32]}$ Moreover, the absence of fuzzy features points towards the absence of adsorbates at the $\mathrm{Cu}$ edges, again supporting a potential-driven roughening process. As the process happens also underneath graphene and at negative potentials, where no re-deposition of atoms is expected, the adatoms nucleating in the upper terraces might originate and diffuse from the grain boundaries. Further studies looking at the kinetics of the process under different electrolytes and $\mathrm{pH}$ conditions are underway, to asses if potential-driven reconstructions ${ }^{[33]}$ as a kinetic phenomenon might be a general explanation for surface transformations observed on $\mathrm{Cu}$ and other metals during $\mathrm{HER} / \mathrm{CO}_{2} \mathrm{RR}^{\left[{ }^{[34]}\right.}$

Finally, we performed a preliminary study comparing the $\mathrm{CO}_{2} \mathrm{RR} / \mathrm{HER}$ performance of the g-CuNCs to a Highly-Oriented Pyrolytic Graphite (HOPG) substrate (as a representative model system of the graphene layer) and to a pristine g-Cu sample. Linear sweep voltammograms corrected for electrochemically active surface area (ESCA) in a $\mathrm{CO}_{2}$-saturated $0.1 \mathrm{M} \mathrm{KHCO}_{3}$ are shown in Figure 3d. At negative potentials, cathodic current densities increase exponentially due to the $\mathrm{CO}_{2} \mathrm{RR}$ and the parasitic HER. This effect is especially pronounced for g-CuNCs; where the presence of CuNCs underneath graphene leads to a shift in the $\mathrm{HER} / \mathrm{CO}_{2} \mathrm{RR}$ onset potentials to more positive values and increase the current density more than twice compared to the pristine g-Cu sample. These preliminary experiments hint that asprepared g-CuNCs could show an enhanced $\mathrm{HER} / \mathrm{CO}_{2} \mathrm{RR}$ performance due to the unique combination of the (100) facets and confinement effects ${ }^{[35,36]}$ at the $\mathrm{Cu} /$ graphene interface.

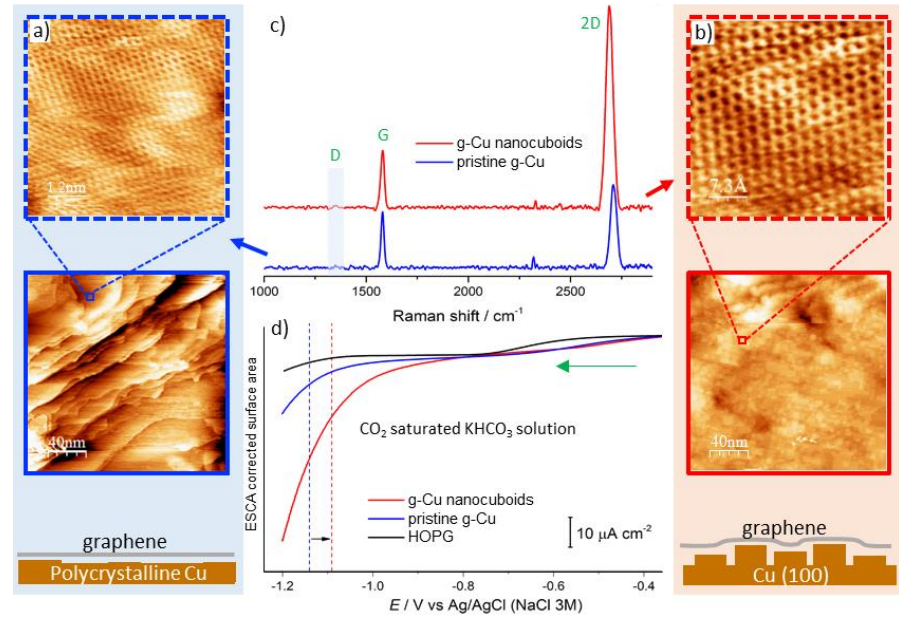

Figure 3. Ex-situ STM images showing graphene a) before and b) after reconstruction to g-CuNCs. $U_{b}=0.1 \mathrm{mV}, I=10.5 \mathrm{nA}$. c) Ex-situ Raman spectra of pristine g-Cu and g-CuNCs. Gray band highlights the wavenumber where the $D$ band is usually observed. d) ESCA-corrected linear sweep voltammograms obtained for pristine g-Cu, g-CuNCs and HOPG.

In summary, we show that $\mathrm{Cu}$ surfaces suffer a drastic reconstruction under long exposure to negative potential values, evolving from polycrystalline $\mathrm{Cu}$ to nanocuboids, even in halidefree electrolytes. To prevent this massive reconstruction under operando conditions, we demonstrate the protective character of a single graphene layer on the $\mathrm{Cu}$ catalysts. The size of the nanocuboids can be tuned by the applied potential and/or the polarization time; e.g. $4 \pm 1 \mathrm{~nm}$ g-CuNCs can be prepared after 4 $\mathrm{h}$ of polarization at $-1 \mathrm{~V}$ vs Pt. A dynamic observation of the gradual surface reconstruction from polycrystalline $\mathrm{Cu}$ to nanocuboids is reported by in-situ EC-STM. As STM measurements cannot be performed in massively reconstructed $\mathrm{Cu}$, this model system is ideal for in-situ studies. By both operando and ex-situ Raman spectroscopy, we show that the graphene layer on $\mathrm{g}$-Cu remains intact during this process. This study opens new avenues to reinterpret the mechanism of nanostructured $\mathrm{Cu}$-based materials without the presence of oxidized Cu species nor halides. In particular, it sheds light on the fact that $\mathrm{Cu}$ catalysts when normalized by the electrochemically active surface area (ECSA) show similar intrinsic activity ${ }^{[34]}$; most likely because the surface morphology (although highly dynamic) and step density under operando conditions are very similar at the atomic scale: the scale where ultimately $\mathrm{CO}_{2} \mathrm{RR}$ occurs. 


\section{Acknowledgements}

This work has received funding from the European Union's Horizon 2020 research and innovation program under grant agreement No. 732840 A-LEAF. FD, RG-M and NL additionally acknowledge funding from European Union's Horizon 2020 research and innovation program under grant agreement No. 722614 ELCOREL and from the Spanish Ministry of Science and Innovation (Grant RTI2018-101394-B-I00).

Keywords: $\mathrm{CO}_{2}$ electroreduction - Copper electrocatalysis • Operando surface chemistry $\bullet$ Kinetic roughening $\bullet$ Graphene $•$

[1] X. Lim, Nat. News 2015, 526, 628.

[2] Y. Hori, A. Murata, R. Takahashi, S. Suzuki, J. Chem. Soc. Chem. Commun. 1988, 17-19.

[3] A. A. Peterson, F. Abild-Pedersen, F. Studt, J. Rossmeisl, J. K. Nørskov, Energy Environ. Sci. 2010, 3, 1311-1315.

[4] K. P. Kuhl, E. R. Cave, D. N. Abram, T. F. Jaramillo, Energy Environ. Sci. 2012, 5, 7050-7059.

[5] Y. Hori, A. Murata, R. Takahashi, S. Suzuki, J. Am. Chem. Soc. 1987 109, 5022-5023.

[6] A. Bagger, W. Ju, A. S. Varela, P. Strasser, J. Rossmeisl, ACS Catal. 2019, 9, 7894-7899.

[7] A. Loiudice, P. Lobaccaro, E. A. Kamali, T. Thao, B. H. Huang, J. W. Ager, R. Buonsanti, Angew. Chem. Int. Ed. 2016, 55, 5789-5792.

[8] Y. Wang, Z. Wang, C.-T. Dinh, J. Li, A. Ozden, M. Golam Kibria, A. Seifitokaldani, C.-S. Tan, C. M. Gabardo, M. Luo, H. Zhou, F. Li, Y. Lum, C. McCallum, Y. Xu, M. Liu, A. Proppe, A. Johnston, P. Todorovic, T.-T. Zhuang, D. Sinton, S. O. Kelley, E. H. Sargent, Nat. Catal. 2020, 3, 98106.

[9] Y. Kwon, Y. Lum, E. L. Clark, J. W. Ager, A. T. Bell, ChemElectroChem 2016, 3, 1012-1019.

[10] R. Kas, R. Kortlever, H. Yılmaz, M. T. M. Koper, G. Mul, ChemElectroChem 2015, 2, 354-358.

[11] C. S. Chen, A. D. Handoko, J. H. Wan, L. Ma, D. Ren, B. S. Yeo, Catal. Sci. Technol. 2014, 5, 161-168.

[12] D. Kim, C. S. Kley, Y. Li, P. Yang, Proc. Natl. Acad. Sci. 2017, 114, 10560-10565

[13] H. Jung, S. Y. Lee, C. W. Lee, M. K. Cho, D. H. Won, C. Kim, H.-S. Oh, B. K. Min, Y. J. Hwang, J. Am. Chem. Soc. 2019, DOI 10.1021/jacs.8b11237.

[14] J. Huang, N. Hörmann, E. Oveisi, A. Loiudice, G. L. D. Gregorio, O. Andreussi, N. Marzari, R. Buonsanti, Nat. Commun. 2018, 9, 3117.

[15] Y.-G. Kim, J. H. Baricuatro, A. Javier, J. M. Gregoire, M. P. Soriaga, Langmuir ACS J. Surf. Colloids 2014, 30, 15053-15056.

[16] C. M. Gunathunge, X. Li, J. Li, R. P. Hicks, V. J. Ovalle, M. M. Waegele, J. Phys. Chem. C 2017, 121, 12337-12344.

[17] Y.-G. Kim, J. H. Baricuatro, M. P. Soriaga, Electrocatalysis 2018, 1-5.

[18] P. Grosse, D. Gao, F. Scholten, I. Sinev, H. Mistry, B. Roldan Cuenya, Angew. Chem. Int. Ed. n.d., 57, 6192-6197.

[19] T. Möller, F. Scholten, T. N. Thanh, I. Sinev, J. Timoshenko, X. Wang, Z. Jovanov, M. Gliech, B. R. Cuenya, A. S. Varela, P. Strasser, Angew. Chem. Int. Ed. 2020, 59, 17974-17983.

[20] Y. Li, F. Cui, M. B. Ross, D. Kim, Y. Sun, P. Yang, Nano Lett. 2017, 17, 1312-1317.

[21] J. Hong, S. Lee, S. Lee, H. Han, C. Mahata, H.-W. Yeon, B. Koo, S.-I. Kim, T. Nam, K. Byun, B.-W. Min, Y.-W. Kim, H. Kim, Y.-C. Joo, T. Lee, Nanoscale 2014, 6, 7503-7511.

[22] S. Chen, L. Brown, M. Levendorf, W. Cai, S.-Y. Ju, J. Edgeworth, X. LI, C. W. Manguson, A. Velamakanni, R. D. Pinert, J. Kang, J. Park, R. S. Ruoff, ACS Nano 2011, 5, 1321-1327.

[23] S. M. Kim, A. Hsu, Y.-H. Lee, M. Dresselhaus, T. Palacios, K. K. Kim, J. Kong, Nanotechnology 2013, 24, 365602.

[24] X. Yin, Y. Li, F. Ke, C. Lin, H. Zhao, L. Gan, Z. Luo, R. Zhao, T. F. Heinz, Z. Hu, Nano Res. 2014, 7, 1613-1622.
[25] U. Lee, Y. Han, S. Lee, J. S. Kim, Y. H. Lee, U. J. Kim, H. Son, ACS Nano 2020, 14, 919-926.

[26] S. B. Scott, T. V. Hogg, A. T. Landers, T. Maagaard, E. Bertheussen, J. C. Lin, R. C. Davis, J. W. Beeman, D. Higgins, W. S. Drisdell, C. Hahn, A. Mehta, B. Seger, T. F. Jaramillo, I. Chorkendorff, ACS Energy Lett. 2019, 4, 803-804.

[27] S. D. Costa, A. Righi, C. Fantini, Y. Hao, C. Magnuson, L. Colombo, R. S. Ruoff, M. A. Pimenta, Solid State Commun. 2012, 152, 1317-1320.

[28] A. Thevenon, A. Rosas-Hernández, J. C. Peters, T. Agapie, Angew. Chem. Int. Ed. 2019, 58, 16952-16958.

[29] R. L. Schwoebel, E. J. Shipsey, J. Appl. Phys. 1966, 37, 3682-3686.

[30] G. Ehrlich, F. G. Hudda, J. Chem. Phys. 1966, 44, 1039-1049.

[31] J. C. Girard, Y. Samson, S. Gauthier, S. Roussel, J. Klein, Surf. Sci. 1994 302, 73-80.

[32] J. B. Hannon, C. Klünker, M. Giesen, H. Ibach, N. C. Bartelt, J. C. Hamilton, Phys. Rev. Lett. 1997, 79, 2506-2509.

[33] A. S. Dakkouri, D. M. Kolb, in Interfacial Electrochem. Theory Exp. Appl. (Ed.: A. Wieckowski), Marcel Dekker Inc., New York, 1999, pp. 151-173.

[34] S. Nitopi, E. Bertheussen, S. B. Scott, X. Liu, A. K. Engstfeld, S. Horch, B. Seger, I. E. L. Stephens, K. Chan, C. Hahn, J. K. Nørskov, T. F. Jaramillo, I. Chorkendorff, Chem. Rev. 2019, DOI 10.1021/acs.chemrev.8b00705.

[35] H. Li, J. Xiao, Q. Fu, X. Bao, Proc. Natl. Acad. Sci. 2017, 114, 59305934

[36] J. Wordsworth, T. M. Benedetti, A. Alinezhad, R. D. Tilley, M. A. Edwards, W. Schuhmann, J. Justin Gooding, Chem. Sci. 2020, 11, 1233-1240. 
